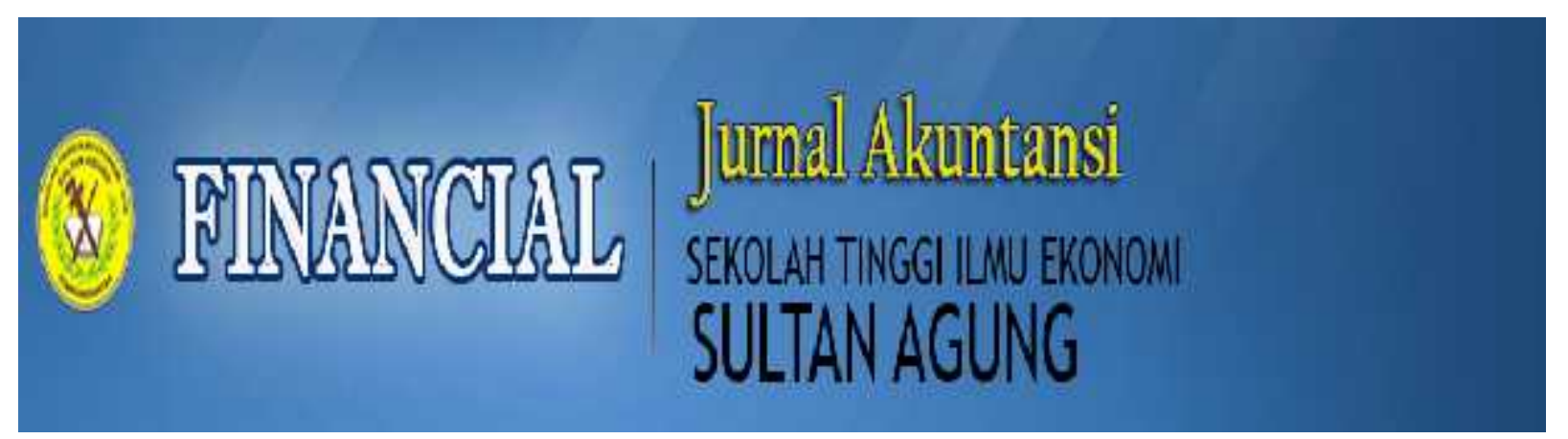

\title{
FAKTOR-FAKTOR YANG MEMPENGARUHI RETURN SAHAM INVESTOR PADA PERUSAHAAN SUB SEKTOR SEMEN YANG TERDAFTAR DI BURSA EFEK INDONESIA
}

\author{
Oleh : \\ Novita Ovianti \\ S1 Akuntansi \\ Yansen Siahaan, Elly Susanti, Astuti
}

\section{Abstrak}

Tujuan dari penelitian ini adalah untuk mengetahui: 1. Faktor-faktor apa saja yang mempengaruhi return saham sebelum uji faktor faktor pada Perusahaan Sub Sektor Semen yang Terdaftar di Bursa Efek Indonesia. 2. Gambaran faktor-faktor yang mempengaruhi return saham setelah uji faktor pada Perusahaan Sub Sektor Semen yang Terdaftar di Bursa Efek Indonesia. 3. Pengaruh faktor-faktor yang mempengaruhi return saham setelah uji faktor pada Perusahaan Sub Sektor Semen yang Terdaftar di Bursa Efek Indonesia baik secara simultan maupun parsial.

Hasil penelitian ini dapat disimpulkan sebagai berikut: 1. Rata-rata current ratio (CR) dan return on asset (ROA) mengalami penurunan, rata-rata debt equity to ratio (DER) cenderung meningkat, ratarata price to book value (PBV) dan rata-rata return saham berfluktuasi cenderung menurun. 2. Hasil analisis regresi linier berganda diketahui bahwa CR dan PBV berpengaruh positif terhadap return saham sedangkan DER dan ROA berpengaruh negatif terhadap return saham. 3. Hasil analisis koefisien korelasi dan korelasi determinasi dapat diambil kesimpulan bahwa hubungan antara CR, DER, ROA dan PBV terhadap return saham berhubungan kuat dan sisanya dipengaruhi oleh variabel lain yang tidak dijelaskan dalam penelitian ini. 4. Pengujian hipotesis secara simultan dapat disimpulkan bahwa hipotesis $\mathrm{HO}$ ditolak yang artinya CR, DER, ROA dan PBV berpengaruh signifikan terhadap return saham pada Perusahaan Sub Sektor Semen.

Saran dari penelitian ini adalah penting bagi perusahaan untuk tetap menjaga kestabilan nilai $\mathrm{CR}, \mathrm{DER}, \mathrm{ROA}, \mathrm{PBV}$ dan return saham. Sebaiknya perusahaan mengevaluasi kinerja keuangannya dengan meningkatkan pengembalian dividen agar investor lebih tertarik untuk menanamkan saham kepada perusahaan.

Kata Kunci : Current Ratio (CR), Debt to Equity Ratio (DER), Return on Asset (ROA), Price to Book Value (PBV), Return Saham.

\section{Abstract}

The purpose of this research are: 1.To find out what are the factors that influence to stock return before the factor test in Sub Sector Cement Companies listed on the Indonesia stock exchange. 2. The description of the factors that influence the stock return after the factor test in Sub Sector Cement Companies listed on the Indonesia stock exchange. The influence factors towards to stock return on company Sub Sectors of cement listed on the Indonesia stock exchange after testing both factors simultaneously and partially

The results of this research can be summed up as follows:1. The average current ratio (CR) and return on asset $(R O A)$ are decreasing, the average debt-to-equity ratio (DER) are likely to be increased, the average price to book value (PBV) and return of the stock are tends to decrease. 2 . Multiple linear regression results that $C R$ and $P B V$ positive influence against the stock return while the $D E R$ and ROA influence negatively to stock return. 3. Analysis of the correlation coefficient and the determination of the correlation to be drawn the conclusion that the relationship between $C R, D E R$, $R O A$ and PBV against the stock return are strongly related and the rest were influenced by other variables that are not described in this study. 4. The simultant hypothesis test can be concluded that the HO hypothesis is rejected, meaning that CR, DER, ROA and PBV has significant influence on stock return.

The advice from the research are, it's important for companies to keep the stability of the CR, $D E R, R O A, P B V$ and the stock return values. It's better for company to evaluate the company's financial performance by improving returns of divident to make investors more interesting to invest stock to the company.

Keywords: Current Ratio (CR), Debt to Equity Ratio (DER), Return on Assets (ROA), Price to Book Value (PBV), Stock Return. 


\section{PENDAHULUAN}

\subsection{Latar Belakang Masalah}

Saham merupakan jenis investasi yang lebih banyak dipilih oleh para investor karena lebih memiliki peluang return yang lebih tinggi. Return merupakan tingkat pengembalian yang diperoleh dari investasi, return saham merupakan tingkat pengembalian atas penanaman modal berupa saham yang diperoleh dari selisih kenaikan atau selisih penurunan harga saham. Imbalan yang diterima investor dalam penanaman saham meliputi jual beli saham, jika keuntungan meningkat disebut capital gain dan jika mengalami penurunan atau rugi disebut capital loss.

Adapun faktor- faktor yang dapat mempengaruhi return saham dapat dilihat pada Tabel 1.1 menunjukkan gambaran current ratio (CR), debt to equity ratio (DER), return on asset $(\mathrm{ROA})$, price to book value (PBV) dan return saham pada Perusahaan Sub Sektor Semen yang terdaftar di Bursa Efek Indonesia periode 2011-2017.

Tabel 1

Gambaran Current Ratio (CR), Debt to Equity Ratio (DER), Return on Asset (ROA), Price to

Book Value (PBV) dan Return Saham pada

Perusahaan Sub Sektor Semen yang Terdaftar di Bursa Efek Indonesia Periode 2011-2017

\begin{tabular}{|c|c|c|c|c|c|}
\hline Tahun & $\begin{array}{c}\text { CR } \\
\text { (Kali) }\end{array}$ & $\begin{array}{c}\text { DER } \\
\text { (Kali) }\end{array}$ & $\begin{array}{c}\text { ROA } \\
\text { (Kali) }\end{array}$ & $\begin{array}{c}\text { PBV } \\
\text { (Kali) }\end{array}$ & $\begin{array}{c}\text { Return } \\
\text { Saham } \\
\text { (Kali) }\end{array}$ \\
\hline $\mathbf{2 0 1 1}$ & 3,70 & 0,32 & 0,17 & 3,62 & 0,11 \\
\hline $\mathbf{2 0 1 2}$ & 3,05 & 0,36 & 0,17 & 4,02 & 0,37 \\
\hline $\mathbf{2 0 1 3}$ & 2,89 & 0,42 & 0,14 & 3,01 & $-0,12$ \\
\hline $\mathbf{2 0 1 4}$ & 2,58 & 0,50 & 0,13 & 2,58 & 0,15 \\
\hline $\mathbf{2 0 1 5}$ & 2,38 & 0,53 & 0,10 & 2,27 & $-0,29$ \\
\hline $\mathbf{2 0 1 6}$ & 2,09 & 0,68 & 0,07 & 1,60 & $-0,18$ \\
\hline $\mathbf{2 0 1 7}$ & 1,94 & 0,84 & 0,02 & 2,04 & 0,18 \\
\hline $\begin{array}{c}\text { Rata- } \\
\text { rata }\end{array}$ & $\mathbf{2 , 6 6}$ & $\mathbf{0 , 5 2}$ & $\mathbf{0 , 1 1}$ & $\mathbf{2 , 7 3}$ & $\mathbf{0 , 0 3}$ \\
\hline
\end{tabular}

Sumber: $w w w . i d x . c o . i d$, data diolah

Dari Tabel 1.1 dapat dilihat bahwa rata-rata CR, DER, ROA, PBV dan return saham mengalami fluktuasi selama periode 20112017. Untuk nilai $C R$ mengalami penurunan yang diikuti oleh peningkatan nilai return saham. Sedangkan pada nilai DER mengalami kenaikan dari tahun ke tahun. Untuk nilai ROA mengalami fluktuasi dan cenderung menurun.

Untuk nilai PBV cenderung mengalami penurunan, sedangkan return saham cenderung meningkat. Dari hal tersebut dapat dikatakan bahwa dari keempat variabel merupakan variabel yang dapat mempengaruhi return saham sebelum dilakukannya uji faktor.

\subsection{Rumusan Masalah}

1. Faktor-faktor apa saja yang mempengaruhi return saham sebelum uji faktor pada Perusahaan Sub Sektor Semen yang terdaftar di Bursa Efek Indonesia.

2. Bagaimana gambaran faktor-faktor yang mempengaruhi return saham setelah uji faktor pada Perusahaan Sub Sektor Semen yang terdaftar di Bursa Efek Indonesia.

3. Bagaimana pengaruh faktor-faktor yang mempengaruhi return saham setelah uji faktor pada Perusahaan Sub Sektor Semen yang terdaftar di Bursa Efek Indonesia baik secara simultan maupun parsial.

\subsection{Tujuan Penelitian}

1. Untuk mengetahui faktor-faktor apa saja yang mempengaruhi return saham sebelum uji faktor pada Perusahaan Sub Sektor Semen yang terdaftar di Bursa Efek Indonesia.

2. Untuk mengetahui gambaran faktorfaktor yang mempengaruhi return saham setelah uji faktor pada Perusahaan Sub Sektor Semen yang terdaftar di Bursa Efek Indonesia.

3. Untuk mengetahui pengaruh faktor-faktor yang mempengaruhi return saham setelah uji faktor pada Perusahaan Sub Sektor Semen yang terdaftar di Bursa Efek Indonesia baik secara simultan maupun parsial.

\subsection{Metode Penelitian}

Penelitian ini menggunakan data sekunder dengan cara mengakses dari situs http://www.idx.co.id. Desain penelitian ini adalah penelitian kepustakaan (library research). Teknik analisis data yang digunakan adalah uji faktor, uji asumsi klasik, analisis deskriptif kualitatif, analisis deskriptif kuantitatif.

\section{LANDASAN TEOR}

\subsection{Akuntansi}

\subsubsection{Pengertian Akuntansi}

Pendapat Rudianto (2009:6) tentang akuntansi yaitu sistem informasi yang menghasilkan laporan kepada pihak-pihak yang berkepentingan mengenai kegiatan ekonomi dan kondisi suatu perusahaan".

$$
\text { Sedangkan Mursyidi (2010:17) }
$$
berpendapat tentang akuntansi, "proses pengidentifikasian data keuangan, pengolahan dan penganalisisan data yang relevan untuk diubah menjadi informasi yang dapat digunakan untuk decision making".

\subsubsection{Tujuan Akuntansi}

Menurut Mursyidi (2010:19), tujuan utama akuntansi adalah menyajikan informasi ekonomi dari suatu entitas kepada pihak-pihak yang berkepentingan.

Sedangkan menurut Soemarso (2009:3), tujuan utama akuntansi adalah menyajikan informasi ekonomi (economic information) dari satu kesatuan ekonomi (economic entity) kepada pihak-pihak yang berkepentingan. Informasi ekonomi yang dihasilkan berguna bagi pihak-pihak di dalam perusahaan itu sendiri maupun pihak-pihak di luar perusahaan.

\subsection{Analisa Laporan Keuangan}


Menurut Halim (2007:156), ada beberapa cara yang dapat digunakan untuk menganalisis laporan keuangan perusahaan, tetapi analisis rasio merupakan hal sangat umum digunakan, yang menghubungkan dua data keuangan (neraca atau laporan laba rugi), baik secara individual atau kombinasi dari keduanya, dengan cara membagi satu data dengan data lainnya.

Menurut Sudana (2011:20), analisis laporan keuangan penting dilakukan untuk mengetahui kekuatan dan kelemahan suatu perusahaan. Informasi ini diperlukan untuk mengevaluasi kinerja yang dicapai manajemen perusahaan di masa lalu, dan juga bahan pertimbangan dalam menyusun rencana perusahaan ke depan.

\subsection{Rasio Keuangan}

Menurut Syahyunan (2015:103), "rasio keuangan merupakan rasio yang digunakan untuk mengidentifikasi kondisi keuangan dan kinerja keuangan perusahaan. Disebut rasio karena yang dilakukan pada dasarnya adalah membandingkan (membagi) antar satu item tertentu dalam laporan keuangan dengan item lainnya".

Kasmir (2012:104) mengungkapkan, "rasio keuangan adalah rasio yang membandingkan angka-angka yang ada dalam laporan keuangan atau antar laporan keuangan. Setelah dilakukan perbandingan, dapat disimpulkan hasil posisi keuangan suatu perusahaan untuk periode tertentu".

\subsection{Return Saham}

Samsul (2006:291) mengemukakan, "return saham adalah pendapatan yang dinyatakan dalam persentase dari modal awal investasi. Pendapatan investasi dalam saham ini meliputi keuntungan jual beli saham, di mana jika untung disebut capital gain dan jika rugi disebut capital loss".

Keown, et. al. (2004:287) mengemukakan bahwa, "return saham merupakan pemilik saham yang paling begantung pada peningkatan atau penurunan harga saham sebagai sumber pengembalian". Sedangkan menurut Hartono (2000:215), "return saham merupakan hasil yang diperoleh dari suatu investasi".

\subsection{Faktor-Faktor yang Mempengaruhi \\ Return Saham}

Menurut Samsul (2006:200), faktorfaktor yang dapat mempengaruhi return saham yaitu faktor makro dan faktor mikro. Faktor makro merupakan faktor yang ada di luar perusahaan, tetapi memiliki pengaruh terhadap kenaikan atau penurunan kinerja perusahaan baik secara langsung atau tidak langsung. Faktor mikro meliputi laba bersih per saham, laba usaha per saham, nilai buku per saham, rasio ekuitas terhadap utang, rasio laba bersih terhadap ekuitas, cash flow per saham, dan rasio keuangan lainnya. Rasio keuangan lainnya seperti current ratio, quick ratio, cash ratio, inventory turnover, dan account receivable turnover. Jika rasio keuangan sangat baik tetapi hasil akhirnya yang tercermin dalam laba per saham, rasio ekuitas terhadap utang, dan return on equity sangat rendah maka hal itu tidak berarti apa-apa bagi investor. Harga yang terlalu rendah menyatakan bahwa kinerja manajemen perusahaan kurang baik. Namun bila return saham terlalu tinggi dapat mengurangi kemampuan investor untuk membeli saham, sehingga menimbulkan return saham sulit untuk meningkat lagi.

\section{PEMBAHASAN}

3.1. Analisis

\subsubsection{Uji Faktor}

KMO and Bartlett's Test

\begin{tabular}{|c|c|c|}
\hline \multicolumn{2}{|c|}{$\begin{array}{l}\text { Kaiser-Meyer-Olkin Measure of } \\
\text { Sampling Adequacy. }\end{array}$} & 689, \\
\hline $\begin{array}{l}\text { Bartlett's Test } \\
\text { of Sphericity }\end{array}$ & $\begin{array}{l}\text { Approx. Chi-Square } \\
\text { df } \\
\text { Sig. }\end{array}$ & $\begin{array}{r}57,002 \\
6 \\
, 000\end{array}$ \\
\hline
\end{tabular}

Dari hasil Kaiser-Meiyer-Olkin (KMO) di atas sudah memenuhi syarat yaitu berada di atas 0,50 begitu juga dengan Bartlett's test of sphericity juga signifikan berada di bawah 0,05 . Jadi dapat disimpulkan bahwa analisis faktor dapat diteruskan dan kemudian dilakukan uji Anti-images Matrices.

\begin{tabular}{|ll|r|r|r|r|}
\multicolumn{7}{c|}{ Anti-image Matrices } \\
\hline & & \multicolumn{1}{c|}{ CR } & \multicolumn{1}{c|}{ DER } & \multicolumn{1}{c|}{ ROA } & \multicolumn{1}{c|}{ PBV } \\
\hline \multirow{4}{*}{ Anti-image } & CR &, 482 &, 073 &,- 067 &, 011 \\
Covariance &, 073 &, 366 &, 119 &,- 097 \\
& ROA &,- 067 &, 119 &, 110 &,- 120 \\
& PBV &, 011 &,- 097 &,- 120 &, 193 \\
\hline & CR &, $914^{\mathrm{a}}$ &, 173 &,- 289 &, 036 \\
Anti-image & DER &, 173 &, $705^{\mathrm{a}}$ &, 595 &,- 365 \\
Correlation & ROA &,- 289 &, 595 &, $621^{\mathrm{a}}$ &,- 826 \\
& PBV &, 036 &,- 365 &,- 826 &, $633^{\mathrm{a}}$ \\
\hline
\end{tabular}

a. Measures of Sampling Adequacy(MSA)

Dari hasil nilai Anti-images tersebut dapat diketahui bahwa semua variabel merupakan faktor yang mempengaruhi return saham karena sudah memenuhi syarat nilai Antiimages berada di atas 0,5.

3.1.2. Analisis Deskripsi Kualitatif

1) Gambaran Current Ratio (CR) pada Perusahaan Sub Sektor Semen yang Terdaftar di Bursa Efek Indonesia Periode 2011-2017

Berikut ini gambaran Current Ratio (CR) pada Perusahaan Sub Sektor Semen Periode 2011-2017:

Tabel 3.1

Gambaran CR Perusahaan Sub Sektor Semen yang Terdaftar di Bursa Efek Indonesia Periode 2011-2017

\begin{tabular}{|c|c|c|c|c|c|c|c|c|}
\hline $\begin{array}{c}\text { Kode } \\
\text { Emiten }\end{array}$ & $\mathbf{2 0 1 1}$ & $\mathbf{2 0 1 2}$ & $\mathbf{2 0 1 3}$ & $\mathbf{2 0 1 4}$ & $\mathbf{2 0 1 5}$ & $\mathbf{2 0 1 6}$ & $\mathbf{2 0 1 7}$ & $\begin{array}{c}\text { Rata- } \\
\text { rata } \\
\text { (Kali) }\end{array}$ \\
\hline INTP & $\mathbf{6 , 9 9}$ & 6,03 & 6,15 & 4,93 & 4,89 & 4,53 & 3,70 & 5,32 \\
\hline
\end{tabular}




\begin{tabular}{|c|c|c|c|c|c|c|c|c|} 
SMCB & 1,47 & 1,40 & 0,64 & 0,60 & 0,65 & $\mathbf{0 , 4 6}$ & 0,54 & 0,82 \\
\hline SMGR & 2,65 & 1,71 & 1,88 & 1,60 & 2,21 & 1,27 & 1,57 & 1,84 \\
\hline $\begin{array}{c}\text { Rata- } \\
\text { rata }\end{array}$ & 3,70 & 3,05 & 2,89 & 2,58 & 2,38 & 2,09 & 1,94 & 2,66 \\
\hline \multicolumn{7}{|c|}{ Nilai Minimum CR (Kali) } \\
\hline \multicolumn{7}{c|}{ Rata-rata CR (Kali) } & $\mathbf{0 , 4 6}$ \\
\hline \multicolumn{8}{|c|}{} & $\mathbf{2 , 9 9}$ \\
\hline
\end{tabular}

Sumber : Data Diolah

Berdasarkan Tabel 3.1 diketahui bahwa nilai current ratio (CR) mengalami penurunan dari tahun ke tahun. Hal ini disebabkan oleh peningkatan liabilitas jangka pendek lebih tinggi daripada peningkatan total aset lancarnya.

2) Gambaran Debt to Equity Ratio (DER) pada Perusahaan Sub Sektor Semen yang Terdaftar di Bursa Efek Indonesia Periode 2011-2017

Berikut ini gambaran Debt to Equity Ratio (DER) pada Perusahaan Sub Sektor Semen Periode 2011-2017:

Tabel 3.2

Gambaran DER pada Perusahaan Sub Sektor Semen yang Terdaftar di Bursa Efek Indonesia Periode 2011-2017

\begin{tabular}{|c|c|c|c|c|c|c|c|c|}
\hline $\begin{array}{c}\text { Kode } \\
\text { Emiten }\end{array}$ & $\mathbf{2 0 1 1}$ & $\mathbf{2 0 1 2}$ & $\mathbf{2 0 1 3}$ & $\mathbf{2 0 1 4}$ & $\mathbf{2 0 1 5}$ & $\mathbf{2 0 1 6}$ & $\mathbf{2 0 1 7}$ & $\begin{array}{c}\text { Rata- } \\
\text { rata } \\
\text { (Kali) }\end{array}$ \\
\hline INTP & $\mathbf{0 , 1 5}$ & 0,17 & 0,16 & 0,17 & 0,16 & $\mathbf{0 , 1 5}$ & 0,18 & 0,16 \\
\hline SMCB & 0,45 & 0,45 & 0,70 & 0,96 & 1,05 & 1,45 & $\mathbf{1 , 7 3}$ & 0,85 \\
\hline SMGR & 0,35 & 0,46 & 0,41 & 0,37 & 0,39 & 0,45 & 0,61 & 0,43 \\
\hline $\begin{array}{c}\text { Rata- } \\
\text { rata }\end{array}$ & 0,32 & 0,36 & 0,42 & 0,50 & 0,53 & 0,68 & 0,84 & 0,52 \\
\hline \multicolumn{7}{|c|}{ Nilai Minimum DER (Kali) } & & $\mathbf{0 , 1 5}$ \\
\hline \multicolumn{7}{|c|}{ Raksa-ratam DER (Kali) } \\
\hline \multicolumn{10}{|c|}{ (Kali) } \\
\hline Sumber :
\end{tabular}

Sumber : Data Diolah

Berdasarkan Tabel 3.2 tersebut dapat diketahui bahwa nilai debt to equity ratio (DER) mengalami fluktuasi dan cenderung meningkat. $\mathrm{Hal}$ ini dikarenakan oleh peningkatan total liabilitas lebih tinggi dari peningkatan total ekuitas.

3) Gambaran Return on Asset (ROA) pada Perusahaan Sub Sektor Semen yang Terdaftar di Bursa Efek Indonesia Periode 2011-2017

Berikut ini gambaran Return on Asset (ROA) pada Perusahaan Sub Sektor Semen Periode 2011-2017:

Tabel 3.3

Gambaran ROA pada Perusahaan Sub Sektor Semen yang Terdaftar di Bursa Efek Indonesia Periode 2011-2017

\begin{tabular}{|c|c|c|c|c|c|c|c|c|}
\hline $\begin{array}{c}\text { Kode } \\
\text { Emiten }\end{array}$ & 2011 & 2012 & 2013 & 2014 & 2015 & 2016 & 2017 & $\begin{array}{c}\text { Rata- } \\
\text { rata } \\
\text { (Kalia }\end{array}$ \\
\hline INTP & 0,20 & 0,21 & 0,19 & 0,18 & 0,16 & 0,13 & 0,06 & 0,16 \\
\hline SMCB & 0,10 & 0,11 & 0,06 & 0,04 & & & & 0,04 \\
\hline SMGR & 0,20 & 0,19 & 0,17 & 0,16 & 0,12 & 0,10 & 0,04 & 0,14 \\
\hline $\begin{array}{c}\text { Rata- } \\
\text { rata }\end{array}$ & 0,17 & 0,17 & 0,14 & 0,13 & 0,10 & 0,07 & 0,02 & 0,11 \\
\hline \multicolumn{8}{|c|}{$\begin{array}{l}\text { Nilai Minimum ROA (Kali) } \\
\text { Nilai Maksimum ROA (Kali) }\end{array}$} & $\begin{array}{l}-0,04 \\
0,21\end{array}$ \\
\hline \multicolumn{8}{|c|}{$\begin{array}{l}\text { Nilal Maksimum ROA (Kall) } \\
\text { Rata-rata ROA (Kali) }\end{array}$} & 0,11 \\
\hline
\end{tabular}

Sumber : Data Diolah

Berdasarkan Tabel 3.3 tersebut dapat dilihat bahwa nilai Return on Asset (ROA) perusahaan mengalami penurunan dari tahun ke tahun. Hal ini disebabkan oleh penurunan laba bersih setelah pajak serta kenaikan total aset.

4) Gambaran Price to Book Value (PBV) pada Perusahaan Sub Sektor Semen yang Terdaftar di Bursa Efek Indonesia Periode 2011-2017

Berikut ini gambaran Price to Book Value (PBV) pada Perusahaan Sub Sektor Semen Periode 2011-2017:

Tabel 3.4

Gambaran PBV pada Perusahaan Sub Sektor Semen yang Terdaftar di Bursa Efek Indonesia Periode 2011-2017

\begin{tabular}{|c|c|c|c|c|c|c|c|c|}
\hline $\begin{array}{l}\text { Kode } \\
\text { Emiten }\end{array}$ & 2011 & 2012 & 2013 & 2014 & 2015 & 2016 & 2017 & $\begin{array}{l}\text { Rata- } \\
\text { rata } \\
\text { (Kali) }\end{array}$ \\
\hline INTP & 3,99 & 4,26 & 3,20 & 3,71 & 3,44 & 2,17 & 3,29 & 3,44 \\
\hline SMCB & $\begin{array}{l}\frac{2,59}{2,21} \\
2\end{array}$ & $\begin{array}{l}\frac{4,20}{2,64} \\
\frac{2}{2}\end{array}$ & $\begin{array}{l}\frac{3,0}{1,99} \\
1,99\end{array}$ & & $\frac{3,44}{0,90}$ & & & $\begin{array}{l}\frac{3,44}{1,38} \\
\end{array}$ \\
\hline SMGR & $\frac{2,41}{4,65}$ & $\frac{2,047}{5,18}$ & $\begin{array}{l}3,355 \\
3,85\end{array}$ & 3,84 & 2,46 & $\frac{0,008}{1,78}$ & $\frac{1,03}{1,93}$ & $\begin{array}{l}3,000 \\
3,38\end{array}$ \\
\hline Rata- & 3,62 & 4,02 & 3,01 & 2,58 & 2,27 & 1,60 & 2,04 & 2,73 \\
\hline & 0,19 \\
\hline \multicolumn{8}{|c|}{ Nilai Maksimum PBV (Kali) } & $\begin{array}{l}5,18 \\
27,7\end{array}$ \\
\hline
\end{tabular}

Sumber : Data Diolah

Berdasarkan Tabel 3.4 tersebut dapat dilihat bahwa nilai price to book value (PBV) perusahaan mengalami fluktuasi dan cenderung menurun. Hal ini disebabkan oleh harga pasar saham yang menurun.

5) Gambaran Return Saham pada Perusahaan Sub Sektor Semen yang Terdaftar di Bursa Efek Indonesia Periode 2011-2017

Berikut ini gambaran Return Saham pada Perusahaan Sub Sektor Semen Periode 20112017:

Tabel 3.5

Gambaran Return Saham pada Perusahaan Sub Sektor Semen yang Terdaftar di Bursa Efek Indonesia Periode 2011-2017

\begin{tabular}{|c|c|c|c|c|c|c|c|c|}
\hline $\begin{array}{l}\text { Kode } \\
\text { Emiten }\end{array}$ & 2011 & 2012 & 2013 & 2014 & 2015 & 2016 & 2017 & $\begin{array}{l}\text { Rata } \\
\text {-rata } \\
\text { (Kali }\end{array}$ \\
\hline INTP & 0,09 & 0,33 & $-0,09$ & 0,30 & $-0,05$ & $-0,29$ & 0,49 & 0,11 \\
\hline SMCB & $\begin{array}{l}0,0,01 \\
-0,01\end{array}$ & 0,35 & $-0,20$ & $\begin{array}{l}-0,01 \\
-0,01\end{array}$ & - $-0,53$ & $-0,08$ & & $-0,08$ \\
\hline SMGR & 0,24 & 0,41 & $-0,08$ & 0,17 & $-0,27$ & $-0,17$ & 0,11 & 0,06 \\
\hline Rata- & 0,11 & 0,36 & $-0,12$ & 0,15 & $-0,28$ & $-0,18$ & 0,18 & 0,03 \\
\hline \multicolumn{8}{|c|}{ Nilai Minimum Return Saham } & $\begin{array}{l}-0,53 \\
0 ., 49\end{array}$ \\
\hline
\end{tabular}

Sumber : Data Diolah

Berdasarkan pada Tabel 3.5 dapat dilihat bahwa return saham Perusahaan Sub Sektor Semen mengalami fluktuasi dan cenderung menurun. Hal ini disebabkan oleh harga saham yang menurun.

3.1.3. Analisis Deskrisptif Kuantitatif

3.1.3.1.Regresi Linier Berganda

Analisis regresi linier berganda pada penelitian menggunakan SPSS versi 21 dapat terlihat pada Tabel 5.

Tabel 3.6

Hasil Analisis Regresi Linier Berganda Coefficients $^{\mathrm{a}}$

\begin{tabular}{|l|r|r|r|}
\hline Model & \multicolumn{2}{|c|}{$\begin{array}{c}\text { Unstandardized } \\
\text { Coefficients }\end{array}$} & \multicolumn{1}{c|}{$\begin{array}{c}\text { Standardized } \\
\text { Coefficients }\end{array}$} \\
\cline { 2 - 4 } & \multicolumn{1}{|c|}{ B } & \multicolumn{1}{|c|}{ Std. Error } & \multicolumn{2}{c|}{ Beta } \\
\hline (Constant) &,- 099 &, 167 &, 037 \\
CR &, 005 &, 029 &,- 489 \\
DER &,- 292 &, 162 & $-1,296$ \\
ROA & $-4,450$ & 1,695 & 1,469 \\
\hline
\end{tabular}


Sumber: Hasil Pengolahan Data

Berdasarkan Tabel 3.6 di atas, model persamaan regresi yang diperoleh adalah:

$\hat{Y}=-0,099+0,005 X_{1}-0,292 X_{2}-4,450 X_{3}+$

$$
0,279 X_{4}
$$

Artinya terdapat pengaruh yang positif antara CR dan PBV terhadap return saham, dan terdapat pengaruh negatif antara DER dan ROA terhadap return saham pada Perusahaan Sub Sektor Semen yang Terdafar di Bursa Efek Indonesia Periode 2011-2017.

\subsubsection{Koefisien Korelasi dan Determinasi} Tabel 3.7

Koefisien Korelasi dan Koefisien Determinasi Model Summary

\begin{tabular}{|l|c|r|r|c|}
\hline Model & $\mathrm{R}$ & $\mathrm{R}$ Square & $\begin{array}{c}\text { Adjusted } \\
\text { R Square }\end{array}$ & $\begin{array}{c}\text { Std. Error of the } \\
\text { Estimate }\end{array}$ \\
\hline 1 &, $756^{\mathrm{a}}$ &, 572 &, 465 &, 19017 \\
\hline
\end{tabular}

a. Predictors: (Constant), PBV, DER, CR, ROA

b. Dependent Variable: R SAHAM

Sumber: Hasil Pengolahan Data

Berdasarkan Tabel 3.7 terlihat bahwa nilai $r$ adalah 0,756 yang berarti bahwa terdapat korelasi atau hubungan yang kuat antara variabel return saham dengan variabel independennya (CR, DER, ROA, dan PBV). Sementara koefisien determinasi $(R)$ adalah 0,572 berarti $57,2 \%$ return saham dijelaskan oleh keempat variabel independen (CR, DER, ROA, dan PBV), sedangkan sisanya $42,8 \%$ dijelaskan oleh variabel lainnya yang tidak dimasukkan dalam penelitian ini seperti variabel lain yaitu rasio keuangan lainnya, faktor makro, tingkat inflasi dan lain-lain.

\subsubsection{Uji Hipotesis}

1) Uji Simultan (Uji F)

Hasil uji F dapat dilihat pada Tabel 3.8.

Tabel 3.8

Hasil Uji F

ANOVA $^{a}$

\begin{tabular}{|l|r|r|r|r|r|}
\hline Model & $\begin{array}{c}\text { Sum of } \\
\text { Square } \\
\text { s }\end{array}$ & df & $\begin{array}{c}\text { Mean } \\
\text { Squar } \\
\mathrm{e}\end{array}$ & $\mathrm{F}$ & Sig. \\
\hline $\begin{array}{l}\text { Regres } \\
\text { sion }\end{array}$ &, 773 & 4 &, 193 & $\begin{array}{r}5,34 \\
7\end{array}$ & $\begin{array}{r}, 006 \\
\mathrm{~b}\end{array}$ \\
$\begin{array}{l}\text { Residu } \\
\text { al } \\
\text { Total }\end{array}$ &, 579 & 16 &, 036 & & \\
\hline
\end{tabular}

a. Dependent Variable: R_SAHAM

b. Predictors: (Constant), PBV, DER, CR,

ROA

Sumber: Hasil Pengolahan Data

Dari hasil perhitungan Tabel 3.8 dapat dilihat bahwa nilai $F_{\text {tabel }}=3,01$, maka $F_{\text {hitung }}$ $>F_{\text {tabel }}=(5,347>3,01)$ atau Sig $<0,05$ ( $0,006<0,05)$. Maka dapat disimpulkan bahwa $\mathrm{H}_{\mathrm{U}}$ ditolak yang berarti bahwa CR, DER, ROA, PBV berpengaruh signifikan terhadap return saham pada Perusahaan Sub Sektor Semen yang terdaftar di Bursa Efek Indonesia Peiode 2011-2017.
2) Uji Parsial (Uji t)

Hasil uji t dapat dilihat pada Tabel 3.9.

Tabel 3.9

Hasil Uji t

Coefficients $^{\mathrm{a}}$

\begin{tabular}{|c|c|c|}
\hline Model & $t$ & Sig. \\
\hline $\begin{array}{ll} & \text { (Constant) } \\
\text { CR } \\
1 \quad \text { DER } \\
\text { ROA } \\
\text { PBV }\end{array}$ & $\begin{array}{r}-, 591 \\
, 155 \\
-1,808 \\
-2,625 \\
3,944\end{array}$ & $\begin{array}{l}, 563 \\
, 879 \\
, 089 \\
, 018 \\
, 001\end{array}$ \\
\hline
\end{tabular}

a. Dependent Variable: R_SAHAM

Sumber: Hasil Pengolahan Data

Dari Tabel 3.9 CR diperoleh $t_{\text {hitung }}<t_{\text {tabel }}$ atau $0,155<2,11991$ dengan taraf signifikan $0,879>0,05$, maka $\mathrm{H}_{0}$ diterima yang artinya bahwa $\mathrm{CR}$ berpengaruh tidak signifikan terhadap Return Saham. DER diperoleh thitung $^{<}$ $t_{\text {tabel }}$ atau 1,808 $<2,11991$ dengan taraf

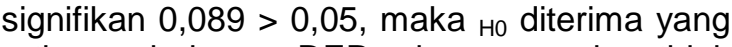
artinya bahwa DER berpengaruh tidak signifikan terhadap Return Saham.

ROA diperoleh $t_{\text {hitung }}>t_{\text {tabel }}$ atau 2,625 > 2,11991 dengan taraf signifikan 0,018<0,05, maka $\mathrm{H}_{0}$ ditolak yang artinya bahwa $\mathrm{ROA}$ berpengaruh signifikan terhadap Return Saham. PBV diperoleh $t_{\text {hitung }}>t_{\text {tabel }}$ atau 3,944 $>2,11991$ dengan taraf signifikan 0,001<0,05, maka $\mathrm{H}_{0}$ ditolak yang artinya PBV berpengaruh signifikan terhadap Return Saham.

\section{Evaluasi}

4.1.Evaluasi Current Ratio (CR) pada

Perusahaan Sub Sektor Semen yang

Terdaftar di Bursa Efek Indonesia

Periode 2011-2017

Dari hasil penelitian terlihat bahwa CR perusahaan mengalami penurunan dari tahun ke tahun. Penurunan ini disebabkan oleh peningkatan liabilitas jangka pendek lebih tinggi dari peningkatan total aset lancarnya. $\mathrm{Hal}$ ini dikarenakan utang bank yang meningkat tetapi tidak digunakan untuk tujuan yang produktif melainkan untuk membayar utang jatuh tempo serta pembangunan dan perbaikan pabrik. Dimana CR minimum perusahaan pada PT Hocim Indonesia, Tbk (SMCB). Apabila nilai CR dikatakan terlalu tinggi dapat diartikan bahwa perusahaan kelebihan aset lancar atau ada penggunaannya yang tidak optimal.

4.2. Evaluasi Debt to Equity Ratio (DER)

pada Perusahaan Sub Sektor Semen yang Terdaftar di Bursa Efek Indonesia Periode 2011-2017

Hasil penelitian menunjukkan terlihat bahwa DER perusahaan berfluktuasi dan cenderung meningkat. Hal ini disebabkan oleh peningkatan total liabilitas lebih tinggi dari peningkatan total ekuitas. Peningkatan total 
liabilitas disebabkan oleh peningkatan utang pihak ketiga. Dimana DER minimum perusahaan pada PT Indocement Tunggal Prakasa (INTP). Meningkatnya nilai DER dari tahun ke tahun menandakan bahwa perusahaan beroperasi dengan menggunakan hutang dari pihak kreditor.

4.3. Evaluasi Return on Asset (ROA) pada Perusahaan Sub Sektor Semen yang Terdaftar di Bursa Efek Indonesia Periode 2011-2017

Hasil penelitian menunjukkan terlihat bahwa ROA perusahaan mengalami penurunan dari tahun ke tahun. Hal ini disebabkan oleh penurunan laba bersih setelah pajak dan kenaikan total aset. penurunan laba bersih setelah pajak yang disebabkan oleh kerugian selisih kurs pada pembayaran utang, kenaikan beban pokok penjualan dan penurunan penjualan. Sementara kenaikan aset disebabkan oleh kenaikan aset tetap.Dimana ROA minimum perusahaan pada PT Holcim Indonesia, Tbk (SMCB). Hal ini disebabkan oleh penurunan laba bersih setelah pajak yang disebabkan oleh kerugian selisih kurs pada pembayaran utang.

4.4.Evaluasi Price to Book Value (PBV) pada Perusahaan Sub Sektor Semen yang Terdaftar di Bursa Efek Indonesia Periode 2011-2017

Dari hasil penelitian terlihat bahwa PBV perusahaan cenderung menurun. Penurunan ini disebabkan oleh harga pasar saham yang menurun. Hal ini berarti perusahaan tersebut dihargai lebih rendah daripada nilai bukunya atau dikatakan bahwa tingkat kepercayaan investor untuk menanamkan sahamnya lebih rendah dari nilai rata-rata. Menurunnya harga saham disebabkan oleh menurunnya profitabilitas perusahaan karena laba bersih perusahaan menurun. Dimana PBV minimum perusahaan pada PT Holcim Indonesia, Tbk (SMCB). Berarti setiap harga saham dihargai lebih rendah dari nilai bukunya.

\subsection{Evaluasi Return Saham pada \\ Perusahaan Sub Sektor Semen yang \\ Terdaftar di Bursa Efek Indonesia \\ Periode 2011-2017}

Berdasarkan hasil peneilitian terlihat bahwa return saham perusahaan cenderung menurun. Hal ini disebabkan oleh harga saham yang menurun. Harga saham menurun karena profitabilitas perusahaan menurun. Profitabilitas menurun karena laba bersih menurun. Dimana return saham minimum perusahaan pada PT Holcim Indonesia, Tbk (SMCB) artinya perusahaan mengalami kerugian atau capital loss yang disebabkan oleh harga saham tahun ini lebih rendah dari harga saham tahun sebelumnya.

\section{KESIMPULAN DAN SARAN}

\subsection{Kesimpulan}

1. Berdasarkan uji faktor yang telah dilakukan variabel current ratio (CR), debt to equity ratio (DER), return on asset ( $\mathrm{ROA})$ dan price to book value (PBV) merupakan faktor yang dapat mempengaruhi return saham sebelum maupun setelah uji faktor.

2. Berdasarkan hasil penelitian secara keseluruhan nilai rata-rata $\mathrm{CR}$ mengalami penurunan dari tahun ke tahun, hal ini dikarenakan peningkatan liabilitas jangka pendek lebih tinggi dari peningkatan total aset lancarnya. Nilai minimum CR terdapat pada perusahaan PT Holcim Indonesia, Tbk (SMCB) pada tahun 2016, sedangkan nilai maksimum CR terdapat pada perusahaan PT Indocement Tunggal Prakarsa, Tbk (INTP) pada tahun 2011.

3. Berdasarkan hasil penelitian secara keseluruhan nilai rata-rata DER mengalami fluktuasi dan cenderung meningkat, hal ini dikarenakan oleh peningkatan total liabilitas lebih tinggi dari peningkatan total ekuitas. Nilai minimum DER terdapat pada perusahaan PT Indocement Tunggal Prakarsa, Tbk (INTP) pada tahun 2011 dan 2016, sedangkan nilai maksimum DER terdapat pada perusahaan PT Holcim Indonesia, Tbk (SMCB) pada tahun 2017.

4. Berdasarkan hasil penelitian secara keseluruhan nilai rata-rata ROA mengalami penurunan dari tahun ke tahun, hal ini disebabkan oleh penurunan laba bersih setelah pajak serta kenaikan total aset. Nilai minimum ROA terdapat pada perusahaan PT Holcim Indonesia, Tbk (SMCB) pada tahun 2017, sedangkan nilai maksimum ROA terdapat pada perusahaan PT Indocement Tunggal Prakasa, Tbk (INTP) pada tahun 2012.

5. Berdasarkan hasil penelitian secara keseluruhan nilai rata-rata PBV mengalami fluktuasi dan cenderung menurun, hal ini disebabkan oleh harga pasar saham yang menurun. Nilai minimum PBV terdapat pada perusahaan PT Holcim Indonesia, Tbk (SMCB) pada tahun 2014, sedangkan nilai maksimum PBV terdapat pada perusahaan PT Semen Indonesia (Persero), Tbk (SMGR) pada tahun 2012.

6. Berdasarkan hasil penelitian secara keseluruhan nilai rata-rata return saham mengalami fluktuasi dan cenderung menurun, hal ini disebabkan oleh harga saham yang menurun. Nilai minimum return saham terdapat pada perusahaan PT Holcim Indonesia, Tbk (SMCB) pada tahun 2015, sedangkan nilai maksimum return saham terdapat pada perusahaan PT Indocement Tunggal Prakasa, Tbk (INTP) pada tahun 2017. 
7. Dari hasil pengujian regresi linear sederhana diketahui bahwa CR dan PBV berpengaruh positif terhadap return saham sedangkan DER dan ROA berpengaruh negatif terhadap return saham.

8. Dari hasil uji koefisien korelasi dan determinasi CR, DER, ROA, dan PBV diketahui bahwa terdapat korelasi atau hubungan yang kuat antara CR, DER, ROA dan PBV terhadap return saham sedangkan selebihnya dinyatakan oleh variabel lain yang tidak dimasukkan dalam penelitian ini.

9. Dari hasil uji $F$ dapat disimpulkan bahwa CR, DER, ROA dan PBV berpengaruh signifikan terhadap return saham pada Perusahaan Sub Sektor Semen yang Terdaftar di Bursa Efek Indonesia (BEI).

10.Dari hasil uji $t$ dapat disimpulkan bahwa nilai $\mathrm{CR}$ berpengaruh tidak signifikan terhadap return saham, nilai DER berpengaruh tidak signifikan terhadap return saham, ROA berpengaruh sinifikan terhadap return saham dan PBV berpengaruh sinifikan terhadap return saham pada Perusahaan Sub Sektor Semen yang Terdaftar di Bursa Efek Indonesia periode 2011-2017.

\subsection{Saran}

1. Sebaiknya perusahaan menggunakan utangnya untuk kegiatan operasional agar dapat meningkatkan penjualan dan laba bersih perusahaan.

2. Perusahaan sebaiknya lebih menggunakan asetnya daripada mengoperasikan perusahaannya dengan menggunakan hutang yang berasal dari pihak luar, dengan tingkat nilai DER yang rendah maka akan lebih meningkatkan kepercayaan investor dalam menanamkan sahamnya kepada perusahaan tersebut.

3. Sebaiknya perusahaan agar meningkatkan penjualan dengan cara memperbanyak produksi, mengurangi beban pokok penjualan dengan cara meminimalisir biaya perawatan pabrik dan dengan melakukan strategi hedging yaitu cara agar melindungi dana trader dari fluktuasi nilai tukar mata uang yang tidak menguntungkan untuk menghindari kerugian kurs.

4. Perusahaan sebaiknya meningkatkan penjualan agar laba bersih perusahaan meningkat dengan itu profitabilitas juga akan meningkat sehingga investor akan tertarik untuk menanamkan saham nya pada perusahaan tersebut.

5. Perusahaan sebaiknya lebih memperhatikan kinerja keuangannya kembali dengan meningkatkan pengembalian dividen yang menjadi hak para pemegang saham dengan begitu para investor akan lebih mempertimbangkan untuk menanamkan saham nya kepada
Perusahaan Sub Sektor Semen yang

Terdaftar di Bursa Efek Indonesia (BEI).

\section{DAFTAR PUSTAKA}

Astuti, Dewi. 2004. Manajemen Keuangan Perusahaan. Jakarta: Ghalia Indonesia.

Bursa Efek Indonesia, http: //www.idx.co.id. Tahun akses 2018

Ginting, Suriani dan Erward. 2013. Analisis Faktor-Faktor yang Mempengaruhi Return Saham pada Perusahaan Manufaktur yang Terdaftar di Bursa Efek Indonesia. Medan: Jurnal Wira Ekonomi Mikroskil, Vol. 3, No. 01. STIE Mikroskil.

http: //www.mikroskil.ac.id/ejurnal/index.php/ jwern/article/view/19. 24 Mei 2018

Ghozali, Imam. 2016. Aplikasi Analisis Multivariate dengan Program IBM SPSS 23. Semarang: BPFE Universitas Diponegoro.

Halim, Abdul. 2007. Manajemen Keuangan Bisnis. Bogor: Ghalia Indonesia.

Harahap, Sofyan Syafri. 2010. Analisis Kritis atas Laporan Keuangan. Jakarta: Rajawali Pers.

Hartono, Jogiyanto. 2000. Teori Portofolio dan Analisis Investasi, Edisi kedua. Yogyakarta: UPP AMP YKPN.

Hermawan, Wildan Arif. 2016. Analisis Pengaruh Faktor Fundamental Terhadap Return Saham Pada Perusahaan Property dan Real Estate di Bursa Efek Indonesia (BEI). Yogyakarta:Universitas Negeri Yogyakarta. Skripsi.

Hery. 2015. Analisis Laporan Keuangan. Edisi Satu. Yogyakarta: Center for Academic Publishing Service.

Kasmir. 2012. Analisis Laporan Keuangan. Edisi 1-5. Jakarta:Rajawali Pers.

Keown, Arthur. J, et. al. 2004. Manajemen Keuangan. Edisi 9. Jakarta: Indeks.

Manurung, Ruspinondang. Rhenata. Ignatia. 2015. Analisis Pengaruh Likuiditas, Profitabilitas, Leverage dan Aktivitas Terhadap Return Saham Studi Empiris di Perusahaan Manufaktur yang Terdaftar di Bursa Efek Indonesia (BEI) Tahun 20082013. Yogyakarta: Universitas Sanata Dharma. Skripsi

Mulyadi. 2009. Sistem Akuntansi. Jakarta: Salemba Empat.

Munawir, S 2004. Analisa Laporan Keuangan. Edisi keempat, Cetakan Ketigabelas. Yogyakarta: Liberty.

Mursyidi. 2010. Akuntansi Dasar. Bogor: Ghalia Indonesia.

Rudianto. 2009. Pengantar Akuntasi. Jakarta: Erlangga. 
Saham ok. www.sahamok.com: Tahun akses 2018.

Sandi, Roey. 2010. Studi Empiris tentang Faktor-Faktor yang Mempengaruhi Return Saham pada Industri Food and Beverages di Bursa Efek Indonesia (BEI). Jakarta:UIN Syarif Hidayatullah. Skripsi.

Samsul, Mohammad. 2006. Pasar Modal dan Manajemen Portofolio. Jakarta: Erlangga.

Simbolon, Hotman. 2009 Yogyakarta: Graha IImu.

Soemarso, S.R. 2009. Akuntansi Suatu Pengantar. Buku Ke 2. Edisi 5. Jakarta: Salemba Empat.

Subramanyam, K. R dan John J. Wild. 2010. Analisis Laporan Keuangan : Financial Statement Analysis. Buku Satu, Edisi Sepuluh. Jakarta : Salemba Empat.

Sugiyono. 2010. Metode Penelitian (Kuantitatif, Kualitatif, dan R\&D). Bandung: Alfabeta.

Suliyanto. 2011. Ekonomika Terapan: Teori dan Aplikasi dengan SPSS. Yogyakarta: Andi.
Syahyunan. 2015. Manajemen Keuangan 1. Edisi Ketiga. Medan: USU Press.

Tampubolon, Manahan P. 2005. Manajemen Keuangan (Finance Management). Bogor: Ghalia Indonesia.

Thamrin, Yulris. 2012. Analisis Current Ratio (CR) dan Debt Equity Ratio (DER) Terhadap Return Saham Perusahaan Manufaktur yang Terdaftar di Bursa Efek Indonesia. Makassar: Universitas Hasanuddin. Skripsi.

Verawati, Rika. 2014. Faktor-Faktor Penentu yang Mempengaruhi Return Saham Perusahaan Manufaktur yang terdaftar di Bursa Efek Indonesia (BEI) Periode 2008-2013. Yogyakarta: Universitas Negeri Yogyakarta. Skripsi.

Yadiati, Winwin dan Ilham Wahyudi. 2010. Pengantar Akuntansi. Edisi Revisi, Cetakan ke-3. Jakarta: Kencana.

Zhang, Zhaouhui. 2015. Financial Ratios and Stock Return on China's Growth Enterprise Market. New York, USA: International Journal of Financial Research Vol. 6, No. 3. Liu Post University. 24 Mei 2018. 